in Cambrian times, and these he terms respectively the Shantung Province (including Manchuria and Shan-si), the Punjab Province (including Yun-nan), and the Siberian Province.

Passing to the description of the new genera and species from China, we cannot help regretting that there is a general absence of individual comparison of the new forms with previously established or wellknown species from other lands. It would have been especially valuable to have had their affinities discussed by Dr. Walcott, with his ripe experience and worldwide knowledge of Cambrian fossils. He indeed expresses the opinion that the excellent illustrations of the new species will enable other investigators to pursue such a study as occasion requires; but no plates or figures, however good, can remedy such a defect in the original descriptions, and this omission robs the memoir of much of its value.

The Ordovician fossils described in the second section by Dr. Weller, have been obtained partly from Shantung and partly from Ssï-ch'uan. The former are very poor and few in number, and no specific determinations were found possible, but their stratigraphical horizon is believed to be Middle Ordovician. The fossils from eastern Ssï-ch'uan are quite different in character and in much better preservation. They were obtained from a thick limestone resting conformably on the Cambrian, and consist chiefly of brachiopods and trilobites, some species of which were described in Igor by Martelli from Shen-si. Richthofen's Ordovician fossils from northern Ssï-ch'uan, collected more than thirty years ago, are regarded as indicating the same geological horizon which Dr. Weller correlates with the Mohawkian (Middle Ordovician) of North America. The fossiliferous Ordovician beds of the central Himalayas, to which he makes no reference, have been regarded as of the same age. There is no similarity to the Ordovician faunas of eastern Yun-nan and Tonkin or of the Northern Shan States, but some species appear comparable or closely allied to Spiti forms; and in southwestern Yun-nan it is probable that the Ssï-ch'uan fauna is represented. A conclusion of special interest at which Dr. Weller arrives is that there is a mixture of North American and Baltic forms in China, as in the Himalayas, where, however, the American element seems to be stronger.

The Carboniferous fauna described by Dr. Girty from Shantung, Shan-si, and Ssï-ch'uan is very scanty and of peculiar facies, but seems remotely allied to Russian and Indian faunas, and is considered to be of Upper Carboniferous (Pennsylvanian) age, with the exception of a few very doubtful fossils. The rich Middle and Upper Carboniferous faunas described by Kayser, Loczy, Mansuy, and Deprat from other parts of China appear to be unrepresented.

$$
\text { F. R. C. REED. }
$$

\section{MARINE BIOLOGY.}

THE life-histories of the Pacific Coast salmon and the halibut caught off the west coast of North America form the subject of two papers just published by Dr. J. P. McMurrich in vol. vii. of the Transactions of the Royal Society of Canada. In this work the author puts the method of scale examination to a somewhat severe test. It is fairly certain that this line of investigation must be regarded only as supplementary to detailed research by means of fishery experiments and statistical studies; such is the experience of most workers in Europe. Yet Dr. McMurrich does not hesitate to describe the conclusions that may be deduced from the study of the scales of twenty-two, or ten, or even three fishes, as

No. 23 I8, VOL. 93] "remarkably definite." The species of Oncorhynchus (the Pacific salmon) spawn only once in their lifetimes. The Pacific halibut becomes mature in its eighth year, and then enters upon a period of reproductive maturity. The ova ripen gradually, and "spawning is not a matter of a few days or even weeks, but is prolonged over, it may be, several years." This is too exceptional and improbable a result to deduce from a microscopic examination of the scales of three fishes, especially when the author admits that practically nothing is known as to the life-history of the halibut in North American waters. It is also incorrect to say that planktonic ova of this fish have not been found in European waters. Less, perhaps, is known about the halibut than most other Pleuronectids, but our ignorance is not such an utter blank as is suggested in the paper noticed.

Part i. of the Journal of the Marine Biological Association, published in November, 1913, contains papers dealing with varied aspects of marine biology. Mr. J. H. Orton, in a most useful paper, describes the functioning of the ciliary mechanisms on the gills of Amphioxus, Ascidians, and Solenomya. English writers, apparently accepting as correct the earlier work of Fol, have described food collection as occurring in the endostyle of Ascidians, the solid particles being then conducted along the peripharyngeal grooves, and so into the dorsal groove. Mr. Orton points out that no food-matter at all is taken up by the endostyle. The latter secretes mucus, which is then driven dorsally over the pharynx to the dorsal groove. Essentially the same mode of functioning of the ciliary tracts occurs both in Amphioxus and Ascidians. The pharynx in these animals, and the gills in Lamellibranch molluscs, are not respiratory mechanisms, but organs which function as waterpumps and food-collectors. In the same number of the journal there is an account of some very interesting experiments made by Mr. J. Gray with the object of investigating the chemical and physical changes which occur when the egg of the sea-urchin is naturally fertilised. The entrance of the sperm into the egg raises the electrical conductivity of the latter, the change attaining a maximum within ten minutes of the addition of the sperms to the ripe eggs. The eggmembrane in the unfertilised condition is remarkably impermeable to electrolytes, its surface being polarised. Probably the entrance of the sperm effects depolarisation and increases the permeability of the membrane to ions, but in some fifteen minutes polarisation again occurs, and the egg returns to its electrical state prior to fertilisation. Five other papers in the journal are written by zoologists of University College, Aberystwyth, and deal with sea-anemones, with the habits of the Galatheidea, and with the littoral fauna of Cardigan Bay. Dr. Th. Mortensen writes also on the development of some British Echinoderms. This number of the journal is altogether a very interesting one.

J. J.

\section{CRYSTALLINE STRUCTURES AS REVEALED BY X-RAYS. ${ }^{1}$}

$T H E$ analysis of crystal structure by means of $\mathrm{X}$-rays depends on the fact that a pencil of $\mathrm{X}$-rays of uniform quality is reflected by a crystal face when, and only when, it meets the face at exactly the proper angle. As we shall see presently, the effect depends on the regularity of the crystal structure according to which the atoms of the crystal are arranged in planes, which are parallel to the face and regularly spaced. There is a certain relation between

1 From a lecture delivered before the Manchester Literary and Philosophical Society on March I8, by Prof. W. H. Bragg, F.R.S. 
the wave-length of the $\mathrm{X}$-radiation, the spacing of the planes, and the proper angle of incidence. If we always use the same rays, and measure the angles at which they are reflected by the different faces of a crystal, natural or prepared, we discover the relative spacings of the many systems of planes which can be drawn regularly through the atoms of the crystal; and hence the actual arrangement of the atoms can be deduced. It is in this way that the structure is analysed.

Let us first consider some details of the reflection effect. The theory is not entirely strange to us, for Lord Rayleigh carefully investigated a strictly analogous phenomenon twenty-five years ago; this was the brilliant coloration of crystals of chlorate of potash. When white light falls on these crystals there is a strong selective reflection of rays the wavelengths of which are confined within very narrow limits. R. W. Wood has prepared crystals which reflect waves the limits of which are no wider apart than the two D lines of sodium. Rayleigh showed that the effect was due to the existence of regularly spaced twinning planes parallel to the reflecting surface. He pointed out the analogy to other physical problems in sound, and in a Friday evening discourse at the Royal Institution he illustrated the effect by reflecting a high-pitched note by a series of parallel muslin sheets stretched tight and evenly spaced.

Rayleigh showed that in these and parallel cases the reflection must be total provided the number of planes was sufficiently great, no matter how feeble the reflection from each plane. In the present case the wave-lengths of X-rays are many thousands of times smaller than the waves of light which Rayleigh used; and the crystal planes being at atomic distances from each other are also many thousands of time closer than the twinning planes of chlorate of potash.

It is found that pencils of homogeneous X-rays suitable for use in the experiment, are contained in the general mass of radiation issuing from an X-ray bulb. The antikathode of the bulb emits "lines" or rays of definite wave-length which are characteristic of the material of which it is made.

The platinum antikathode gives a spectrum containing five sharply defined and intense lines which stand out well from the general radiation. The osmium spectrum appears to have five similar triplets instead of the five lines of the platinum, the head of each triplet coinciding with a platinum line. Several substances ranging in atomic weight from silver down to calcium emit similar spectra consisting each of two strong lines, increasing regularly in wave-length as the atomic weight decreases. A large number of these have been photographed by Moseley. Bulbs having rhodium or palladium antikathodes have been exceedingly useful in the crystal analysis, as they last well, their line spectra are very intense, and the wavelengths are of convenient magnitude. The principal rhodium line is really double; and it will serve to illustrate the surprising exactness of the reflection effect when it is stated that the two constituents are just separated by reflection at the cleavage face of the diamond. The glancing angles are then $8^{\circ} 35^{\prime}$ and $8^{\circ} 39^{\prime}$.

Let us next consider the application of these principles to the determination of crystal structure. We take first, naturally, the large class of cubic crystals which are not only of high importance, but also of the most simple construction.

The atoms of a crystal can be arranged in the form of a repeated group or pattern. Each group is to be supposed to contain as $f \in W$ atoms as possible consistent with the requirement that the whole crystal can be built by packing these groups together, all the groups being similar and similarly oriented. If a

$$
\text { NO. } 23 \text { I } 8 \text {, VOL. 93] }
$$

point is chosen similarly in each group it serves to indicate the position of that group relative to other groups. An arrangement of points chosen in this way shows the basal structure of the crystal, and is known as a "space lattice."

There are three space lattices which give cubic character to crystals. In the first the representative points are placed at the corners of a cube; the whole lattice consisting of a repetition of this arrangement in all directions in space. In the second there are representative points at the corners of a cube, and the centre of the cube; in the third at the corners of a cube and at the middle points of the faces. The three are called the cubic, the centred cubic, and the facecentred cubic respectively.

These three types of lattice can be at once distinguished from each other by the X-ray method. Suppose we consider three important types of plane which may be drawn through the atoms of a cubic crystal, that is to say, planes perpendicular to $(a)$ a cube edge, (b) a face diagonal, $(c)$ a cube diagonal. If we draw a diagram or build a model we find readily that the relative spacings of the three sets are different in the different crystals, and this causes corresponding differences in the angles of reflection of some standard line.

Proceeding on these lines we come at once to a case of great importance. Rock-salt or sodium chloride and sylvine or potassium chloride have long been known to be of similar construction, though the nature of the construction has been uncertain until now. X-ray analysis shows, however, that the former crystal has the characteristics of the third class of lattice, and the latter of the first. Moreover, it appears that the elementary group or pattern contains the same number of atoms in each case. There is one obvious way of explaining these facts. Suppose that we place chlorine atoms at the corners of a cube and at the centres of the faces and sodium atoms at the middle points of the edges of the cube and at the cube centre, and take this to represent the structure of rock-salt. Potassium chloride may be derived from sodium chloride by replacing the chlorine atoms of the structure by potassium. Now it appears from a number of mutually supporting indications that the contribution of an atom to the reflection effect depends on its atomic weight only. The atoms of potassium and chlorine are of very nearly the same weight, and can be looked on as equivalent. If this is done the structure of potassium chloride is in effect the simple cubic. But there is a great difference between the weight of sodium and chlorine, and the face-centred arrangement of the chlorine atoms taken separately gives its character to the whole rock-salt structure. All this agrees with experiment. But there is more. The presence of the sodium atoms amongst the chlorine, arranged as a matter of fact on a face-centred lattice of their own, modify the purely face-centred character of the spectra, and experiment shows that the modification is exactly such as theory predicts.

It is impossible in a short account to describe in full the work that has or can be done. Moreover, description is difficult without the aid of a plentiful supply of diagrams or models. It will be sufficient to say that the examination of the positions of the spectra, and especially of the relative intensities of the different orders give information which is gradually being interpreted. The simpler crystals have already been analysed, and the structure of many of the more important cubic crystals is known. The more complex structure of the calcite series has been determined, and something has been discovered of the still more difficult structures of sulphur and of quartz. It must be remembered that in all these cases complete analysis requires not merely the determination of the lattice, but, what is far more difficult, the 
arrangement of the atoms in the group which is represented by each point on the lattice.

We may consider certain points of more general interest. The structure of the diamond stands our with some prominence. It is interesting to find that the carbon atoms are arranged in the most beautifully symmetrical pattern, each being at the centre of a regular tetrahedron composed of its four nearest neighbours. Rings of six carbon atoms are a predominating feature. Planes perpendicular to a cube diagonal-the diamond is, of course, a cubic crystalare arranged in a curious way, the spacings being alternately large and small in the proportion of three to one. This leads to the extinction of the second order reflection from these planes. The effect can be readily illustrated optically by ruling a diffraction grating in the corresponding fashion. Zincblende has exactly the same structure as the diamond, but the alternate planes of the kind just mentioned contain alternately zinc atoms alone and sulphur atoms alone. This explains the well-known polarity of the crystal. Iron pyrites has a rather more complicated structure, which explains at once the curious disposition of the striations on its faces. Sulphur has eight interpenetrating lattices, quartz three of silicon and six of oxygen. In each of these two cases there is regular spacing of the lattices along the long axis, but not in other directions.

The atoms of a crystal are not, of course, at rest; the extent of their movements depends on thermal considerations. As the temperature rises the motion increases. According to theory, this must tend to destroy the intensity of the spectra, particularly those of higher order. Experiment confirms the theoretical deduction, and gives some promise of being able to decide between conflicting hypotheses as to the extent of the thermal influence. It is curious to observe the angles of reflection diminish as the crystal expands with heat and the spacings of the planes increase. The method might even be applied to the measurement of coefficients of expansion of crystals.

Lastly, the study of the X-ray spectra emitted by various substances when made the antikathodes of the $\mathrm{X}$-ray bulb gives valuable information respecting atomic structure, and is most skilfully made use of in the investigations which are being conducted in the physical laboratory of the University of Manchester.

\section{UNIVERSITY AND EDUCATIONAL} INTELLIGENCE.

London.-Prof. H. H. Jeffcott has been appointed by the Senate to the chair of engineering tenable at University College, vacated by the appointment of Prof. J. D. Cormack to a professorship at Glasgow. Prof. Jeffcott was educated at Trinity College, Dublin, and is now professor of engineering in the Royal College of Science, Dublin.

The D.Sc. degree in physics has been granted to Dr. E. E. Fournier d'Albe, Royal College of Science and Birmingham University, for a thesis on the efficiency of selenium as a detector of light.

Evidence is to be presented, on behalf of the University, to the Departmental Committee of the Board of Education in regard to external students, without being restricted to the recommendations of the Royal Commission.

Mr. C. A. KING has been appointed professor of mechanical engineering in the Civil Engineering College, Sibpur, India.

A FREE scholarship of the value of $30 l$., tenable at the Northampton Polytechnic Institute (London) is being offered to students. In view of the openings which the calling and craft of optics now offer, this
"Aitchison Memorial Scholars'ip," should prove most attractive to intelligent youths. The subjects of examination include English, mathematics, and elementary physics. Full particlars can be had of the hon. treasurer, Mr. H. F. Purser, 39 Charles Street, Hatton Garden, London, E.C.

A copy has been received from New York City of a volume entitled "A Study of Education in Vermont prepared by the Carnegie Foundation for the Advancement of Teaching at the request of the Vermont Edu. cational Commission." The legislature of Vermont on November 19,1912 , appointed a commission to report on the educational responsibilities of the State. On February 24, I913, the commission invited the Carnegie Foundation to undertake an expert study of the school system of the State, including the higher institutions of learning. The resulting report provides much information and enumerates the conclusions and recommendations of the foundation. Among other recommendations the withdrawal of State subsidies from all higher institutions not owned and controlled by the State is suggested. Three colleges are now subsidised by the State of Vermont, and these have some 1026 students, $56_{5}$ of which are provided by Vermont itself, while 400 Vermont students attend colleges in other States. There are in every thousand of population in Vermont three students of higher education. In connection with the University of Vermont, one of the institutions aided by the State, strong courses in the humanities and in the sciences are recommended, as well as the development by the University of the State Agricultural College.

THE general and departmental reports for the session $1912-13$ of the Bradford Technical College reveal a satisfactory growth in the usefulness of the institution. There was an increase in the attendance over the previous academic year. The arrangement under which advanced students in dyeing from the Leeds University attend a course in the practical dyehouse at Bradford was in work during the session. A number of Bradford students also attended special courses of lectures at the Leeds University. This reciprocal arrangement, having proved satisfactory, is being continued. The head of the department of textile industries reports that although no large increase in the number of day students is to be expected, it is worthy of note that attendance in the department forms a ready entrance into the higher walks of the textile industries in the case of students of ability who lack special influence in the trade. He points out also that the raising of the standard of attainment in the industry is possibly the most important work of the college evening classes, and those who have followed this development recognise the help which the college has rendered to the textile trade of the city in this direction. The worl $\mathrm{x}$ of the materials testing laboratory of the department of engineering is growing at a rapid rate, and at the present time more than one thousand tests per annum are being made for the various Government and corporation departments, and for local firms. This has the effect of bringing the work of the department into close touch with the engineering trade of the district, and a number of interesting problems of a practical character are forthcoming, in the solution of the majority of which the students are permitted to take part.

\section{SOCIETIES AND ACADEMIES. LONDON.}

Royal Society, March 26.-Sir William Crookes, president, in the chair.-J. H. Mummery : The nature of the tubes in marsupial enamel and its bearing upon enamel development. In the present paper the author

NO. 23I8, VOL. 93] 